VIROLOGY JOURNAL

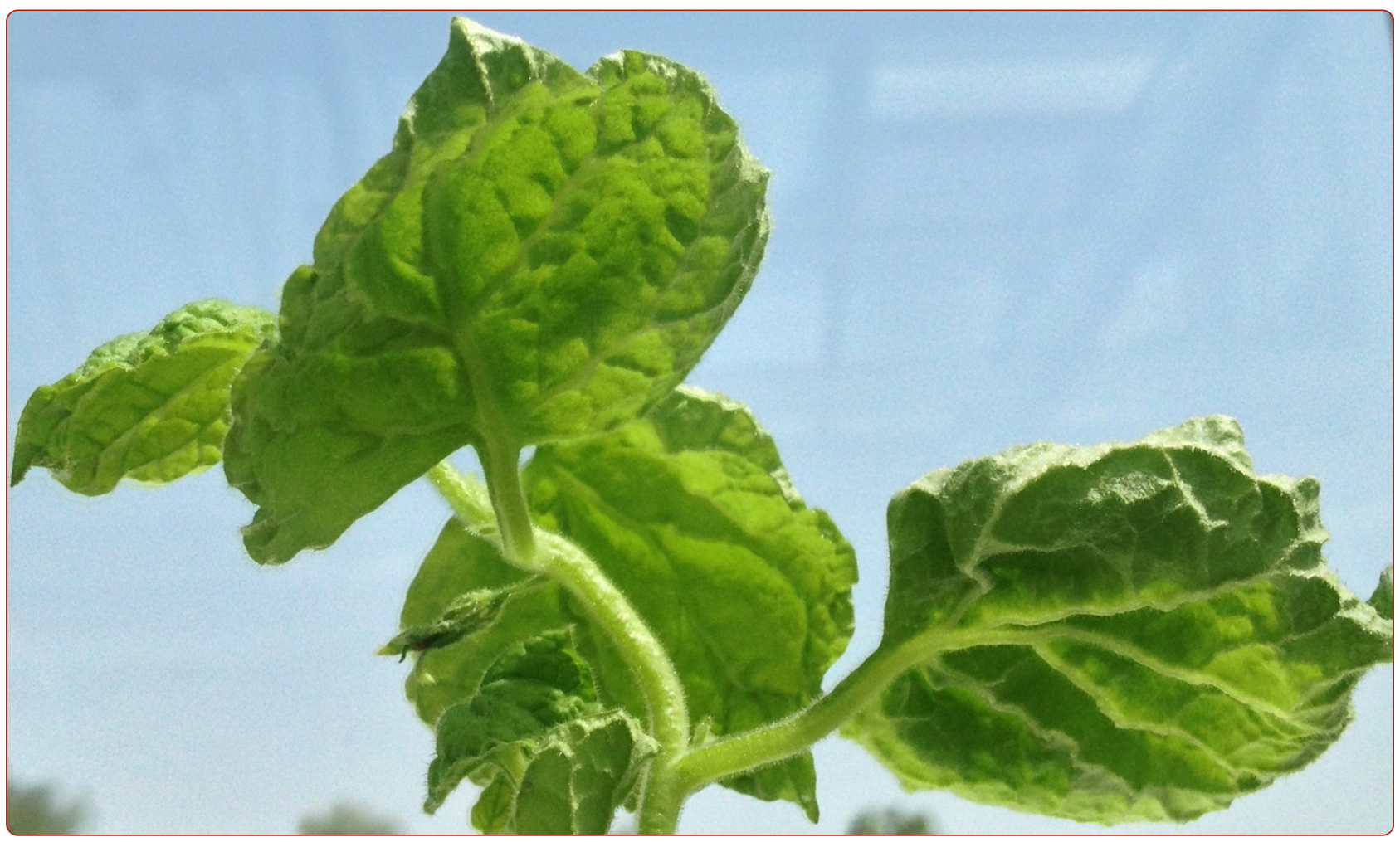

Molecular characterization of a naturally occurring intraspecific recombinant begomovirus with close relatives widespread in southern Arabia

Al-Saleh et al. 


\title{
Molecular characterization of a naturally occurring intraspecific recombinant begomovirus with close relatives widespread in southern Arabia
}

Mohammed A Al-Saleh', Ibrahim M Al-Shahwan', Judith K Brown² and Ali M Idris ${ }^{3^{*}}$

\begin{abstract}
Background: Tomato leaf curl Sudan virus (ToLCSDV) is a single-stranded DNA begomovirus of tomato that causes downward leaf curl, yellowing, and stunting. Leaf curl disease results in significant yield reduction in tomato crops in the Nile Basin. ToLCSDV symptoms resemble those caused by Tomato yellow leaf curl virus, a distinct and widespread begomovirus originating in the Middle East. In this study, tomato samples exhibiting leaf curl symptoms were collected from Gezira, Sudan. The associated viral genome was molecularly characterized, analyzed phylogenetically, and an infectious clone for one isolate was constructed.

Findings: The complete genomes for five newly discovered variants of ToLCSDV, ranging in size from 2765 to 2767-bp, were cloned and sequenced, and subjected to pairwise and phylogenetic analyses. Pairwise analysis indicated that the five Gezira isolates shared $97-100 \%$ nucleotide identity with each other. Further, these variants of ToLCSDV shared their highest nucleotide identity at 96-98\%, 91-95\%, 91-92\%, and 91-92\% with the Shambat, Gezira, Oman and Yemen strains of ToLCSDV, respectively. Based on the high maximum nucleotide identities shared between these ToLCSDV variants from Gezira and other previously recognized members of this taxonomic group, they are considered isolates of the Shambat strain of ToLCSDV. Analysis of the complete genome sequence for these new variants revealed that they were naturally occurring recombinants between two previously reported strains of ToLCSDV. Finally, a dimeric clone constructed from one representative ToLCSV genome from Gezira was shown to be infectious following inoculation to tomato and N. benthamiana plants.

Conclusion: Five new, naturally occurring recombinant begomovirus variants ( $>96 \%$ shared nt identity) were identified in tomato plants from Gezira in Sudan, and shown to be isolates of the Shambat strain of ToLCSDV. The cloned viral genome was infectious in $\mathrm{N}$. benthamiana and tomato plants, and symptoms in tomato closely resembled those observed in field infected tomato plants, indicating the virus is the causal agent of the leaf curl disease. The symptoms that developed in tomato seedlings closely resembled those observed in field infected tomato plants, indicating that ToLCSDV is the causal agent of the leaf curl disease in Gezira.
\end{abstract}

Keywords: Geminivirus, Tomato leaf curl Sudan virus, Virus variability, Whitefly vector

\footnotetext{
* Correspondence: idris@email.arizona.edu

${ }^{3}$ Center for Desert Agriculture, King Abdullah University of Science and

Technology, Thuwal, Saudi Arabia

Full list of author information is available at the end of the article
} 


\section{Background}

Recent studies have shown that several tomato-infecting monopartite begomoviruses are prevalent in the Nile Basin, and in the southern region of the Arabian Peninsula, namely, Yemen and Oman [1]. Thus far, two species have been reported from the Nile Basin, Tomato leaf curl Sudan virus (ToLCSDV) and Tomato yellow leaf curl virus (TYLCV) [2,3], while three species have been recognized in the southern region of Arabia, Tomato leaf curl Oman virus (ToLCOMV), ToLCSDV and TYLCV $[1,4]$. This collective group of monopartite begomoviruses causes extensive damage to tomato (Solanum lycopersicum L.) crops in the arid and semi-arid southern part of the Arabian Peninsula and the Nile Basin $[2,5]$.

Viruses in the genus, Begomovirus (family, Geminiviridae) are transmitted by the whitefly Bemisia tabaci (Genn.), a phloem-feeding aleyrodid in the Order: Hempitera. Begomoviruses are characterized by having a single-stranded circular DNA genome encapsidated in twinned icosahedral particles, and recently, have emerged to cause debilitating diseases to many species of dicotyledonous plants of agricultural importance [6]. They are widespread in uncultivated, endemic and naturalized plant species found in the tropics and subtropics worldwide $[7,8]$. The begomovirus genome is composed of either one (monopartite) or two components (bipartite), the latter being designated DNA-A and DNA-B components [9]. Monopartite and bipartite begomoviruses are present in the Eastern Hemisphere. In contrast, with the exception of the recently introduced Tomato yellow leaf curl virus (and its relatives) [10,11], and those associated with commercially traded ornamentals [8], and at times, sweet potato plants [12], only bipartite begomoviruses are found in the Western Hemisphere [6]. And, in a recent example reported from three locations in South America, the DNA-B component was shown to be dispensable for systemic infection $[13,14]$, whereas, in another study involving infectious DNA-A component, no cognate DNA-B was detected [15].

The genome of monopartite begomoviruses contains certain genes that are functionally homologous to those encoded by the DNA-A component of bipartite genome type, encoding six overlapping open reading frames (ORF), two in the virion sense strand, and four in the complementary sense strand. Transcription of ORFs initiates from sequences in a non-coding region, referred to as the intergenic region (IR). This region also contains the begomoviral structurally conserved hairpin and origin of replication, and two or more virus replication associated protein (Rep)-binding motifs that are essential for viral genome replication [16]. Therefore, linkage of Rep and the IR would be expected during recombination, as well as preserved genome modularity, to enhance the prospects of producing fit and viable progeny [17].
In this study we report the molecular characterization of five new, naturally occurring, recombinant begomovirus variants arising from a putative intraspecific genomic exchange of sequences between two previously known strains of ToLCSDV, and demonstrate infectivity of a genomic clone for one of the variants.

\section{Methods}

Leaf samples were collected from plants exhibiting yellow leaf curl and stunting symptoms growing in a commercial tomato field in Gezira, Sudan during the winter, 2011. Total DNA isolated from the symptomatic tomato plants was used as a template to amplify prospective begomoviral genomic components by rolling circle amplification technology (RCA) using the TempliPhi 100 Amplification Kit (GE Healthcare, Life Sciences, Piscataway, NJ, USA) as previously described $[10,18]$. The RCA product was digested to linearize the genome using EcoRI, cloned into pGEM7Zf + (Promega, Madison, WI) and completely sequenced. The DNA sequence was determined for each of five putative full-length begomoviral genomic clones, and analyzed using BLASTn algorithm to query the GenBank database (NCBI). The nucleotide (nt) sequence for the top 14 hits were included in pairwise comparison using the Species Demarcation Tool software (SDT v.1.0) [19] and phylogenetic analyses.

The aligned sequences were used to construct the phylogenetic trees using maximum Likelihood (ML) option available in PAUP* software [20], using the specific parameters, as described [4,21].

The sequence alignment used in the phylogenetic analyses was also used to identify potential recombinatorial fragments using the RDP2 software [22]. The default search parameters for recombination detection were employed using the highest acceptable probability ( $P$ value) of 0.01 .

A recombinant plasmid (pGez3.1) cloned from the tomato sample Gezira 3, carrying a full-length begomoviral genome, was selected to construct a clone for infectivity using pGreen II [23]. The pGez3.1 clone was digested with EcoRI and BamHI to release a $1191 \mathrm{bp}$ fragment, and with $E c o R I / C l a I$ to release a 2188 bp fragment. The fragments were ligated into pGreenII by inserting the ClaI-BamHI fragments ultimately as a single insert, a process that was mediated by multi-fragment ligation [4] to obtain recombinant plasmid pG-Gez3. The pG-Gez3 was electroporated into Agrobacterium tumefaciens GV3101 and used to agro-infiltrate the leaves of $N$. benthamiana, cultivated tomato, Solanum lycopersicon cultivar M82, and wild tomato S. cheesmaniae accession LA0421, as previously described [4]. The infectivity tests were replicated three times. Viral DNA that accumulated in the subsequently developing (non-inoculated) leaves, following agroinoculation provided evidence of replication as well as local and long distance viral movement in the test plants. Total 
DNA was isolated from the newly expanded leaves of $N$. benthamiana and tomato that developed 7-12 days post-inoculation. Total DNA extracts were subjected to PCR analysis to ascertain begomoviral presence or absence, using 'universal' (core) coat protein primers [7]. The amplicons were cloned and sequenced.

\section{Results and discussion}

The monopartite begomoviral genomes were cloned from the RCA-amplified products obtained using total DNA that was extracted from two different tomato plants (isolates Gez3 and Gez4) collected from Gezira. The plasmid vector contained ligated inserts $(n=5)$ that ranged in size from 2765-bp to 2767-bp. Sequence alignment followed by pairwise comparisons [19] revealed that the five clones shared $97-100 \%$ nt sequence identity. Inspection of the five genomic sequences revealed that they had features like other monopartite begomoviral genomes, based on the size and the characteristic organization of the six ORFs (V1, V2, C1, C2, C3 and C4), and the conserved IR $[6,16]$ (Figure 1). The IRs contained one directly repeated sequence, or iteron, the TATA-box, and the stem-loop and nanonucleotide sequence, TAATATTAC, required for transcription and viral genome replication $[24,25]$. The sequences were used to search the NCBI GenBank database using BLASTn to identify the most closely related and several more distant taxa, which were selected and used as reference sequences (Additional file 1) for pairwise distance and phylogenetic analyses. The nt sequence comparisons revealed that the Gezira tomato isolates shared

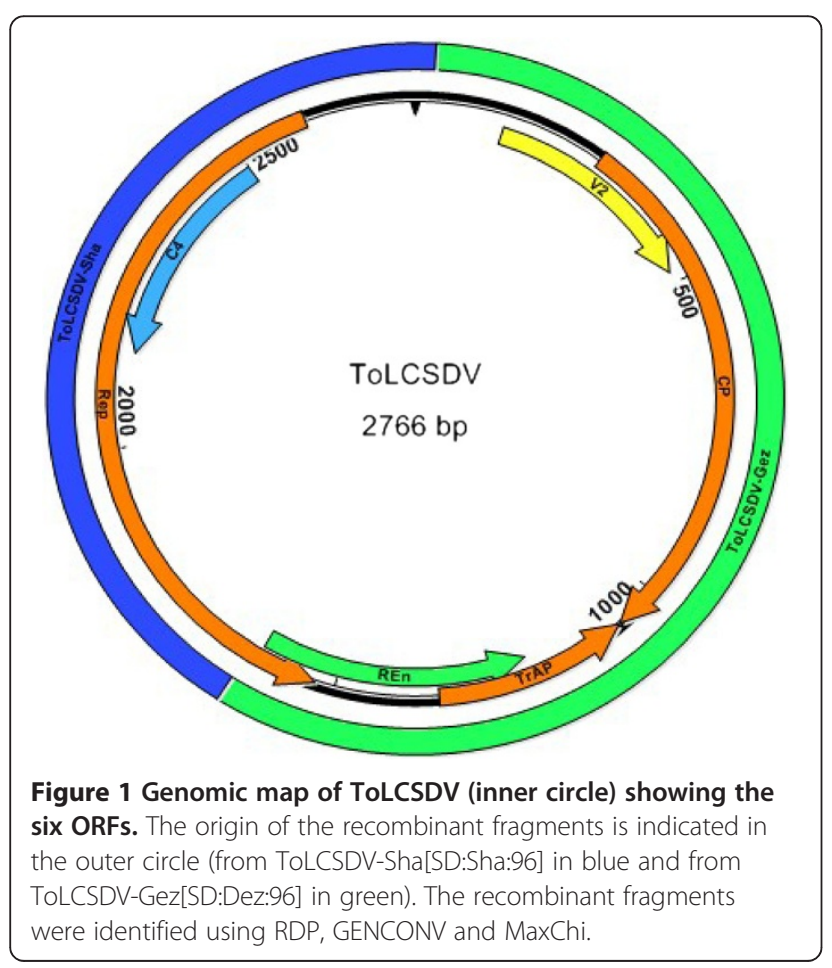

88-96\% nt identity with other ToLCSDV variants (Table 1), which until this report, were known to occur in the Nile Basin [2] and southern Arabia [1]. Further, the Gezira isolates shared $96-97 \%$ identity with the Shambat strain of ToLCSDV, also from the Nile Basin in Sudan.

Based on the ICTV guidelines for species demarcation, at $<91 \%$ nt identity [26], the Gezira tomato isolates are considered variants of ToLCSDV-Sha (Table 1). Even so, the Gezira isolates showed a range of divergence among the three main types of isolates that also group as the ToLCSDV species, including the Oman strain (ToLCSDVMir), at 91-92\%, the Yemen strain (ToLCSDV-Ye), at 9192\%, and the ToLCSDV-Gez1 strain (also endemic to Sudan), at 91-95\% nt identity.

Analysis of the ToLCSDV IR sequence revealed that the Rep-binding iterons, or the repeated 'signature sequences' associated with Rep-binding to initiate begomoviral replication, consisted of imperfect direct repeats (5'-GGTGTATCGGTAC-3'). These iterons were identical to those present in the sequence of the Shambat strain, as shown in Table 1 . The iterons were located between the nt coordinates 2649 and 2661, or five nucleotides upstream of the TATA box of the Rep promoter. Comparative sequence analysis of the Rep gene of the ToLCSDV variants from Gezira, with previously recognized isolates and strains of this virus enabled visual detection of the conserved sequence, FQIN, and its predicted identification as the iteron-related domain (IRD), the predicted amino acid sequences that mediate iteron-Rep molecular interactions [16].

The results of the phylogenetic analysis of aligned begomoviral sequences indicated that all the isolates identified here, and previously recognized strains or variants of ToLCSDV, were members of a single clade (Figure 2; Additional file 2) also containing TYLCV and TYLCV-related begomoviruses extant in the Mediterranean region, North Africa, and the Arabian Peninsula. The five Gezira isolates (Gez3.1, Gez3.2 and Gez3.3 cloned from sample field Gez3 and Gez4.1 and Gez4.2 cloned from field sample Gez4) clustered with other members of the ToLCSDV-Sha strain clade. All of the ToLCSDV sequences grouped with a basis in geographical origin, e.g. either the Nile Basin or Asia, and the latter group was further divided by having an origin in Oman or Yemen. Previous reports have shown that geographical and/or other kinds of physical barriers can contribute importantly to the distribution of begomoviruses [6]. Generally, this group of viruses have been divided into two major groups extant in either the Eastern or Western Hemisphere, with the Eastern Hemisphere genomes (DNA-A or monopartite DNA component) being further separated into subclades, usually, also, exhibiting endemism either in the Far East, Southeast Asia, Africa, North Africa, and/or the Mediterranean region 
Table 1 Comparison of nucleotide sequence percentage identity for Gez3.1 of Tomato leaf curl Sudan virus (ToLCSDVSha[SD:Gez3.1:11]) and other five recognized strains* of the ToLCSDV using Species Demarcation Tool (SDT v1.0) [19]

\begin{tabular}{|c|c|c|c|c|c|c|c|c|c|c|}
\hline \multirow{2}{*}{$\begin{array}{l}\text { Virus } \\
\text { [GenBank accession] }\end{array}$} & \multirow[t]{2}{*}{ Full-length } & \multicolumn{6}{|c|}{ ORF } & \multirow{2}{*}{ IR } & \multirow{2}{*}{$\begin{array}{l}\text { Rep binding } \\
\text { iteron }\end{array}$} & \multirow{2}{*}{$\begin{array}{l}\text { Iteron-related } \\
\text { domain }\end{array}$} \\
\hline & & V1 & V2 & $\mathrm{C2}$ & $\mathrm{C3}$ & C1 & $\mathrm{C4}$ & & & \\
\hline $\begin{array}{l}\text { ToLCSDV } \\
\text { [AY044139] }\end{array}$ & 94 & 99 & 99 & 98 & 98 & 89 & 89 & 71 & GGTGTAGTGGGGT & FKIN \\
\hline $\begin{array}{l}\text { ToLCSDV } \\
\text { [AY044137] }\end{array}$ & 96 & 97 & 93 & 95 & 94 & 99 & 100 & 99 & GGTGTATCGGTAC & FQIN \\
\hline $\begin{array}{l}\text { ToLCSDV } \\
\text { [JF919733] }\end{array}$ & 92 & 97 & 93 & 87 & 88 & 89 & 87 & 86 & TGTATATCGGTAC & FQIN \\
\hline $\begin{array}{l}\text { ToLCSDV } \\
\text { [JF919731] }\end{array}$ & 91 & 95 & 91 & 86 & 90 & 89 & 89 & 86 & TGTATATCGGTAC & FQIN \\
\hline $\begin{array}{l}\text { ToLCSDV } \\
\text { [JN591385] }\end{array}$ & 92 & 97 & 93 & 86 & 87 & 90 & 87 & 81 & GGTACATCGGTAC & FQIY \\
\hline $\begin{array}{l}\text { TYLCV } \\
\text { [AY044138] }\end{array}$ & 88 & 70 & 97 & 95 & 93 & 91 & 88 & 85 & TGTATATCGGTAC & FQIN \\
\hline
\end{tabular}

*Different isolates of ToLCSDV from Gezira (AY044139), Shambat (AY044137), Yemen tomato (JF919731) and Yemen tobacco (JF919733) and Tomato yellow leaf curl virus from Gezira, Sudan (TYLCV). Comparisons are based on the complete genome sequence, and the nucleotide sequence of each individual open reading frame (ORF) (V1, V2, C1, C2, C3, C4) and the intergenic region (IR). The Rep-binding iteron and iteron-related domain for ToLCSDV-Sha[SD:Gez3.1:11] are identical to those for ToLCSDV-Sha[SD:Sha:96] strain (AY044137). Values in bold highlight the highest nucleotide sequence identities with ToLCSDV-Gez3.1 for each ORF or IR compared.

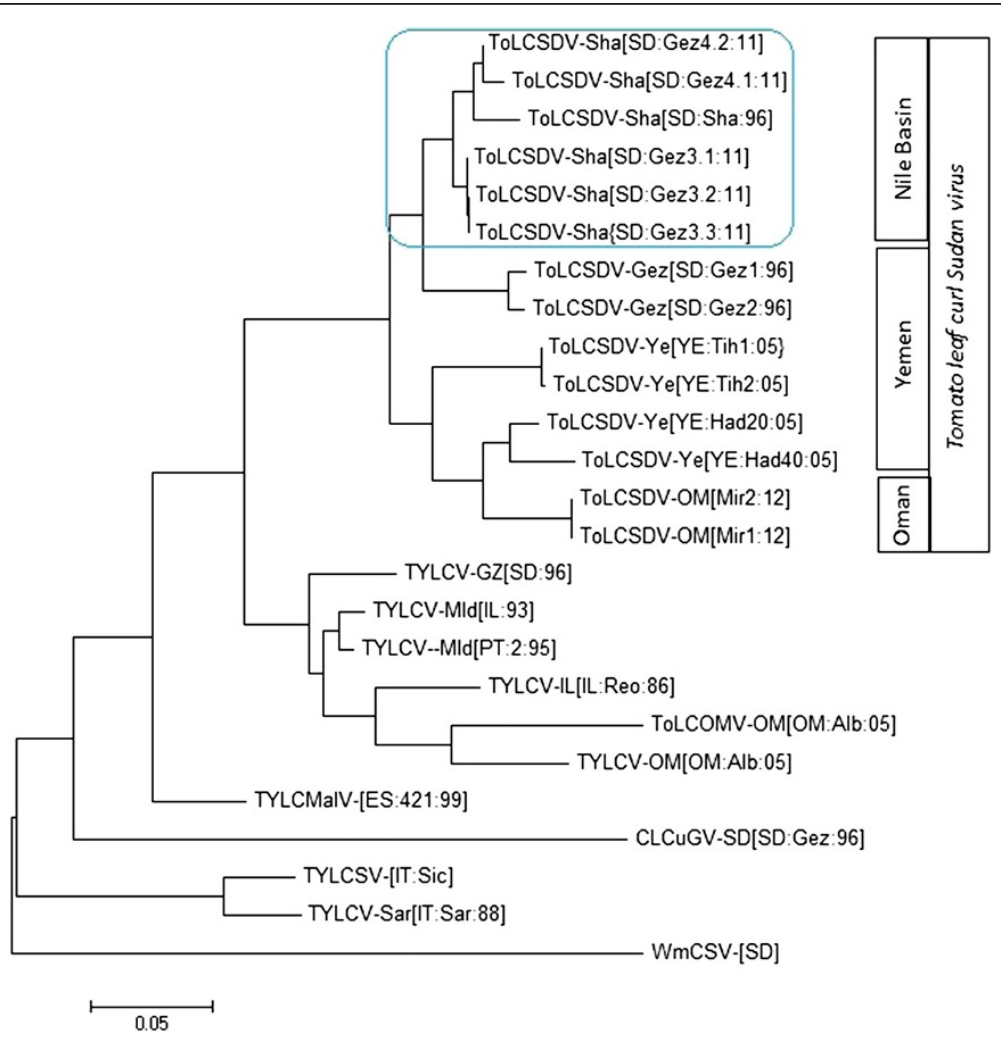

Figure 2 Phylogenetic relationships for news variants of Tomato leaf curl Sudan virus and selected begomoviruses using the maximum likelihood algorithm available in Phylogenetic Analysis Using Parsimony, version 4.0.0b8 [20]. The positions of the ToLCSDV isolates are shaded. Refer to additional table [see Additional file 1] for begomovirus acronyms and GenBank accession numbers and maximum parsimony phylogenetic tree [see Additional file 2] for bootstrap. 
$[2,3,21,27]$. Based on these observations, the ToLCSDV species is likely endemic to the region extending from the Nile Basin to the southern region of the Arabian Peninsula [1].

Recombination analysis was carried out using the program suite available in RDP2 [14]. Three of these algorithms, RDP $\left(P 3.772 \times 10^{-14}\right)$, GENCONV $\left(P 3.604 \times 10^{-14}\right)$, and MaxChi $\left(P 1.446 \times 10^{-10}\right)$, predicted that the genome of the herein five newly described ToLCSDV variants exhibit evidence of intraspecific recombination (Figure 1). The recombination event was confirmed by conducting an independent phylogenetic analysis of the recombinant fragments, which resulted in a shift in tree topology [see Additional file 3]. One predicted recombinant fragment (1199 nt) was located between the nt coordinates $1588-35$, and based on nt sequence was most closely related to the Shambat strain, at $99 \% \mathrm{nt}$ identity, but only $86 \%$ identical to the Gezira strain. The second predicated recombinant fragment (1566 nt in length) was located between the nt coordinates 36-1587, and its sequence was most closely related to the Gezira strain, at $99 \%$ nt identity, compared to its only $93 \%$ shared nt identity with the Shambat strain.

Seedlings of the cultivated tomato cr M18 and the wild tomato accession LA0421 [see Additional file 4], and of the model plant species, $N$. benthamiana, when agro-inoculated with the Shambat isolate of ToLCSDV (pG-Gez3), became systemically infected, based on characteristic viral symptom development. For N. benthamiana, the plants exhibited stunting, leaf curling, vein thickening, and stem deformation, which together resulted in a dwarfed and bushy appearance [see Additional file 5] 7-8 day post-inoculation (DPI). The ToLCSDV-infected 'wild' tomato accession LA0421, exhibited upward curling of the old leaflets, reduced size of new leaflets, and mild vein yellowing, 10-11 DPI. In contrast, the cultivated tomato developed severe curling of new leaflets 11-12 DPI, the symptom phenotype most commonly observed in field infected tomato plants. ToLCSDV presence or absence was confirmed by PCR amplification, and cloning and DNA sequencing of the core region of the viral coat protein (data not show) from total plant DNA extracted from newly developing leaves 12 DPI, thereby fulfilling Koch' postulates for this isolate. In comparison, virus-like symptoms were not observed in the mock-inoculated seedlings of $N$. benthamiana, LA0421, or cv M18.

The leaf curl disease of tomato in Gezira, Sudan (the Nile Basin) has long been associated with begomoviral presence, and isolates of ToLCSDV have been cloned and sequenced from tomato plants collected there as early as 1996 [2]. However, this is the first report of the cloning and sequencing of multiple begomoviral variants from tomato plants exhibiting leaf curl symptoms, and of the demonstrated infectivity of the cloned genome of a representative isolate of ToLCSDV in Gezira, Sudan. Thus, at the time of sample collection, ToLCSDV can be considered the causal agent of the leaf curl disease occurring in tomato crops in Gezira, Sudan. The infectious clone required no associated satellite-like molecule for the development of wild type symptoms in tomato. The development of this infectious ToLCSDV clone provides a whitefly-free approach for rapid resistance screening of tomato germplasm and other solanaceous hosts of the virus. It also provides information inherent in the viral genome sequence that can be used to devise virus- or sequence-specific targets for RNAi-mediated resistance.

\section{Additional files}

\begin{abstract}
Additional file 1: Begomovirus name and acronym [16], and corresponding GenBank accession number for each.

Additional file 2: Phylogenetic relationships for news variants of Tomato leaf curl Sudan virus and selected begomoviruses using the maximum parsimony algorithm available in Phylogenetic Analysis Using Parsimony, version 4.0.0b8 [20]. The positions of the ToLCSDV isolates are shaded. Refer to additional table [see Additional file 1] for begomovirus acronyms and GenBank accession numbers.
\end{abstract}

Additional file 3: Phylogenetic relationships for ToLCSDV-Sha[SD: Gez3.1:11] and other ToLCSDV strains using maximum parsimony (MP) analysis to corroborate the RDP-predicted sites of recombination. Trees show MP results for the (A) fragment (nt 1588-35), and (B) fragment (nt 36-1587). The bootstrap values are shown in major nodes. Arrows indicate shift of predictive parent positions. Refer to additional table [Additional file 1] for begomovirus acronyms and GenBank accession numbers.

Additional file 4: Symptoms of Tomato leaf curl Sudan virus (ToLCSDV-Sha[SD:Gez3.1:11]) in virus-infected tomato plants. The tomato cultivar, M18 (Ali Mahjoub, KAUST, Thuwal, Saudi Arabia), was used for inoculation experiments. Treatments were: (A) ToLCSDV-inoculated, (B) mock-inoculated plant. Wild type accession LA0421 (Ali Mahjoub, KAUST, Thuwal, Saudi Arabia), (C) ToLCSDV-inoculated plant, and (D) mock-inoculated plant.

Additional file 5: Symptoms of Tomato leaf curl Sudan virus (ToLCSDV) in Nicotiana benthamiana plants. (A) TOLCSDV-inoculated plant, (B) close-up of a leaf lower surface of ToLCSDV-inoculated plant, (C) mock-inoculated plant, and (D) close-up of a leaf lower surface of mock-inoculated plant.

Competing interests

The authors declare that they have no competing interests.

\section{Authors' contributions}

AMI collected the samples, cloned and sequenced the new virus variant. All of the authors were awarded funding for this research project, participated in aspects of the experimental design and manuscript preparation including discussion and editing. All of the authors have read and approved the final version of the manuscript.

\section{Acknowledgments}

This study was supported in part by a grant (11-BIO1577-02) from The Long-term Comprehensive National Plan for Science, Technology and Innovation, King Saud University, Saudi Arabia. The authors are thankful to Drs. Phil Mullineaux and Roger Hellens of John Innes Center and Biotechnology and Biological Sciences Research council for providing the pGreen kit.

\section{Author details}

${ }^{1}$ Department of Plant Protection, King Saud University, Riyadh, Saudi Arabia. ${ }^{2}$ School of Plant Sciences, The University of Arizona, Tucson, AZ, USA. ${ }^{3}$ Center 
for Desert Agriculture, King Abdullah University of Science and Technology, Thuwal, Saudi Arabia.

Received: 19 April 2014 Accepted: 27 May 2014

Published: 2 June 2014

\section{References}

1. Idris AM, Abdullah NM, Brown JK: Leaf curl diseases of two solanaceous species in Southwest Arabia are caused by a monopartite begomovirus evolutionarily most closely related to a species from the Nile Basin and unique suite of betasatellites. Virus Res 2012, 169:296-300.

2. Idris AM, Brown JK: Evidence for interspecific-recombination for three monopartite begomoviral genomes associated with the tomato leaf curl disease from central Sudan. Arch Virol 2005, 150:1003-1012.

3. Fauquet CM, Briddon RW, Brown JK, Moriones E, Stanley J, Zerbini M, Zhou X: Geminivirus strain demarcation and nomenclature. Arch Virol 2008, 153:783-821.

4. Idris AM, Shahid MS, Briddon RW, Khan AJ, Zhu J-K, Brown JK: An unusual alphasatellite associated with monopartite begomoviruses attenuates symptoms and reduces betasatellite accumulation. J Gen Virol 2011, 92:706-717.

5. Khan AJ, Idris AM, Al-Saady NA, Al-Mahruki MS, Al-Subhi AM, Brown JK A divergent isolate of tomato yellow leaf curl virus from Oman with an associated DNA beta satellite: an evolutionary link between Asian and the Middle Eastern virus-satellite complexes. Virus Genes 2008, 36:169-176.

6. Fauquet CM, Bisaro DM, Briddon RW, Brown JK, Harrison BD, Rybicki EP, Stenger DC, Stanley J: Revision of taxonomic criteria for species demarcation in the family Geminiviridae, and an updated list of begomovirus species. Arch Virol 2003, 148:405-421.

7. Wyatt SD, Brown JK: Detection of subgroup III geminivirus isolates in leaf extracts by degenerate primers and polymerase chain reaction. Phytopathology 1996, 86:1288-1293.

8. Valverde RA, Sabanadzovic S, Hammond J: Viruses that enhance the aesthetics of some ornamental plants: beauty or beast? Plant Dis 2012, 96:600-611.

9. Stanley J, Bisaro DM, Briddon RW, Brown JK, Fauquet CM, Harrison BD, Rybicki EP, Stenger DC: Geminiviridae. In Virus Taxonomy: Eighth Report of the International Committee on Taxonomy of Viruses. Edited by Fauquet CM, Mayo MA, Maniloff J, Desselberger U, Ball LA. London, UK: Elsevier/ Academic Press; 2005:301-326.

10. Idris AM, Guerrero JC, Brown JK: Two distinct isolates of Tomato yellow leaf curl virus threaten tomato production in Arizona and Sonora, Mexico. Plant Dis 2007, 91:910.

11. Polston J, Bois D, Serra C, Concepcion S: First report of a tomato yellow leaf curl-like geminivirus in the Western Hemisphere. Plant Dis 1994, 78:8.

12. Valverde RA, Clark C: Begomovirus. In Compendium of Sweetpotato Diseases, Pests, and Disorders. 2nd edition. Edited by Clark CA, Ferrin DM, Smith TP, Holmes GJ. St. Paul, MN, USA: The American Phytopathological Society Press; 2013:86-88.

13. Galvão RM, Mariano AC, Luz DF, Alfenas PF, Andrade EC, Zerbini FM, Almeida MR, Fontes EP: A naturally occurring recombinant DNA-A of a typical bipartite begomovirus does not require the cognate DNA-B to infect Nicotiana benthamiana systemically. J Gen Virol 2003, 84:715-726.

14. Hou Y-M, Paplomatas EJ, Gilbertson RL: Host adaptation and replication properties of two bipartite geminiviruses and their pseudorecombinants. Mol Plant-Microbe Interact 1998, 11:208-217.

15. Melgarejo TA, Kon T, Rojas MR, Paz-Carrasco L, Zerbini FM, Gilbertson RL: Characterization of a New World monopartite begomovirus causing leaf curl disease of tomato in Ecuador and Peru reveals a new direction in geminivirus evolution. J Virol 2013, 87:5397-5413.

16. Argüello-Astorga GR, Ruiz-Medrano R: An iteron-related domain is associated to Motif 1 in the replication proteins of geminiviruses: identification of potential interacting amino acid-base pairs by a comparative approach. Arch Virol 2001, 146:1465-1485.

17. Martin DP, Biagini $P$, Lefeuvre $P$, Golden $M$, Roumagnac $P$, Varsani $A$ Recombination in eukaryotic single stranded DNA viruses. Viruses 2011, 3:1699-1738.

18. Inoune-Nagata AK, Albuquerque LC, Roche WB, Nagata T: A simple method for cloning the complete begomovirus genome using the bacteriophage \$29 DNA polymerase. J Virol Methods 2004, 116:209-211.
19. Muhire B, Martin DP, Brown JK, Navas-Castillo J, Moriones E, Zerbini FM, Rivera-Bustamante R, Malathi V, Briddon RW, Varsani A: A genome-wide pairwise-identity-based proposal for the classification of viruses in the genus Mastrevirus (family Geminiviridae). Arch Virol 2013, 158:1411-1424.

20. Swofford DL: PAUP*. Phylogenetic Analysis Using Parsimony (* and Other Methods). Version 4.0610. Sunderland, MA, USA: Sinauer Associates; 2003.

21. Brown JK, Mills-Lujan K, Idris AM: Phylogenetic analysis of Melon chlorotic leaf curl virus from Guatemala: another emergent species in the Squash leaf curl virus Clade. Virus Res 2011, 158:257-262.

22. Martin DP, Williamson C, Posada D: RDP2: recombination detection and analysis from sequence alignments. Bioinformatics 2005, 21:260-262.

23. Hellens RP, Edwards EA, Leyland NR, Bean S, Mullineaux PM: pGreen: a versatile and flexible binary Ti vector for Agrobacterium-mediated plant transformation. Plant Mol Biol 2000, 42:819-832.

24. Eagle PA, Hanley-Bowdoin L: cis element that contribute to Geminivirus transcriptional regulation and the efficiency of DNA replication. J Virol 1997, 71:6947-6955.

25. Sunter G, Bisaro DM: Transcription map of the $B$ genome component of tomato golden mosaic virus and comparison with $\mathrm{A}$ component transcripts. Virology 1989, 173:647-655.

26. Group GS: New species and revised taxonomy proposal for the genus Begomovirus (Geminiviridae): phylogenetic and pairwise distance analysis using the same approach as implemented for the genera Mastrevirus and Curtovirus in the same family (submitted in 2012 and approved in 2013). 2013, vol. 2014:ICTV.

27. Padidam M, Beachy RN, Fauquet CM: Classification and identification of geminiviruses using sequence comparisons. J Gen Virol 1995, 76:249-263.

doi:10.1186/1743-422X-11-103

Cite this article as: Al-Saleh et al: Molecular characterization of a naturally occurring intraspecific recombinant begomovirus with close relatives widespread in southern Arabia. Virology Journal 2014 11:103.

\section{Submit your next manuscript to BioMed Central and take full advantage of:}

- Convenient online submission

- Thorough peer review

- No space constraints or color figure charges

- Immediate publication on acceptance

- Inclusion in PubMed, CAS, Scopus and Google Scholar

- Research which is freely available for redistribution 